\title{
Pengaruh Kompetensi Terhadap Kinerja Guru Pada SMK Kartika X-2
}

\author{
Muhammad Guruh \\ Dosen Fakultas Ekonomi Universitas Pamulang \\ Email : dosen02256@unpam.ac.id
}

\begin{abstract}
ABSTRAK
Tujuan dari penelitian adalah mengetahui pengaruh kompetensi yang berada dilingkup SMK Kartika X-2, untuk mengetahui kinerja guru dan untuk mengetahui seberapa besar pengaruh kompetensi terhadap kinerja guru pada SMK Kartika X-2. Populasi yang digunakan dalam penelitian ini adalah sebanyak 53 pegawai, dengan jumlah sampel dengan teknik penarikan sample teknik sampling jenuh.

Metode penelitian yang digunakan adalah bersifat asosiatif kuantitatif, metode pengumpulan data dengan menyebar kuesioner yang kemudian diolah dengan menggunakan analisis regresi sederhana. Uji yang digunakan untuk menguji instrumen penelitian berupa uji validitas dan uji reliabilitas. Uji regresi linier sederhana, uji kolerasi, uji determinasi dan uji hipotesis menggunakan uji $\mathrm{t}$ dengan bantuan software MICROSOFT EXCEL 2010.

Berdasarkan hasil penelitian pada uji deskriptif diketahui variabel kompetensi mayoritas responden menjawab "sangat setuju" sebesar 50\% dan untuk variabel kinerja guru mayoritas responden menjawab "sangat setuju" sebesar 64\%. Hasil analisis regresi linier sederhana diketahui bahwa nilai $\alpha$ adalah 13,867 , nilai ini menunjukkan bahwa pada saat Kompetensi (X) bernilai 0, maka kinerja guru (Y) akan bernilai 13,867. Sedangkan nilai dari b yaitu 7,222 menunjukkan bahwa ketika terjadi peningkatan kepemimpinan sebesar satu satuan, maka kinerja karyawan akan meningkat sebesar 7,222 satuan. Nilai koefisien kolerasi antara Kompetensi dengan Kinerja guru sebesar 7,222 dan koefisien determinasi sebesar $19,27 \%$. Hal ini menunjukkan bahwa terdapat pengaruh yang cukup kuat antara

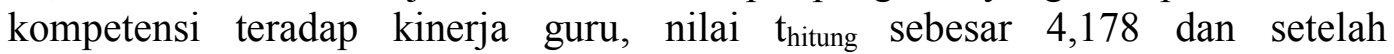
dibandingkan dengan $t_{\text {tabel }}$ pada taraf signifikan 5\% dan derajat kebebasan $n=51$ menunjukkan $t_{\text {tabel }} 2,008$, nilai $t_{\text {hitung }} 4,178>t_{\text {tabel }} 2,008$. Hal ini berarti variabel Kompetensi berpengaruh positif terhadap Kinerja Guru, dan diperoleh hasil signifikan yang menunjukkan nilai $0,000<0,05$ yang berarti terdapat pengaruh yang signifikan antara Kompetensi dan Kinerja Guru. Hal ini menunjukkan $\mathrm{H}_{0}$ ditolak dan $\mathrm{H}_{1}$ diterima.
\end{abstract}

\section{Kata kunci : Kompetensi, Kinerja Guru}




\section{PENDAHULUAN}

\section{A. Latar Belakang Penelitian}

Sekolah Menengah Kejuruan (disingkat smk, bahasa Inggris: HighSchool) adalah salah satu bentuk satuan pendidikan formal yang menyelenggarakan pendidikan kejuruan pada jenjang pendidikan menengah sebagai lanjutan dari SMP/MTs atau bentuk lain yang sederajat atau lanjutan dari hasil belajar yang diakui sama/setara SMP/MTs. Di SMK terdapat banyak sekali Program Keahlian., sama seperti Sekolah Menengah Atas. Yang membedakan antara SMA dengan SMK ialah penempatan jurusan dan praktek yang dilakukan di SMK, siswa/siswi SMK akan didorong untuk memiliki bakat berwirausaha, SMK juga memberikan ilmu tentang pelatihan kerja dan diberikan kemampuan guna menentukan keterampilan pada bidang yang diminati oleh masing-masing siswa/siswi.

Tantangan terbesar Indonesia untuk menumbuhkan perekonomian pada 2017 adalah tenaga kerja (Aviliani, Pengamat Ekonomi dari Indef, 2016). Indonesia dengan pasar yang begitu besar, menjadi salah satu tujuan investasi yang menarik perhatian investor. Yang dengan sendirinya juga menarik perhatian dari para pencari kerja, baik dari dalam negeri maupun dari luar negeri. Dengan kemungkinan semakin membludaknya tenaga kerja asing yang masuk ke Indonesia karena MEA, tentu persaingan menjadi semakin ketat. (manajemensdm.net diakses 13 oktober 2017). Hal ini menjadi dasar untuk mengetahui kompetensi yang di miliki oleh guru-guru disekolah saat mengajar para murid apakah sesuai dengan sertifikasi yang di dapat oleh guru dengan pengaplikasiannya saat mengajar di sekolah, sehingga muridmurid sesudah selesai sekolah benar-benar mendapat ilmu yang berguna untuk bersaing dalam persaingan kerja nantinya.

Berdasarkan latar belakang di atas maka penulis tertarik mengadakan penelitian mengenai "Pengaruh Kompetensi Terhadap Kinerja Guru Pada SMK KARTIKA X-2"

\section{B. Identifikasi Masalah}

Berdasarkan latar belakang masalah yang diuraikan di atas, maka penelitian dapat mengidentifikasi masalah sebagai berikut:

1. Kurangnya sikap yang dimiliki olehguru SMK Kartika X-2

2. Pengetahuan yang masih kurang dimiliki beberapa guru.

3. Kurangnya kemampuan dan sikap yang dimiliki beberapa guru disekolah.

4. Kurangnyakesadaran akan tanggung jawab yang harus di lakukan oleh seorang guru terhadap siswa /siswi yang diajar.

5. Kedisiplinan yang masih rendah dikalangan guru. 


\section{Perumusan Masalah}

Berdasarkan identifikasi dan pembatasan masalah di atas maka diberikan perumusan masalah sebagai berikut:

1. Bagaimana kompetensi guru di SMK Kartika X-2 ?

2. Bagaimana kinerja guru pada SMK Kartika X-2 ?

3. Seberapa besar pengaruh kompetensi terhadap kinerja guru pada SMK Kartika X-2 ?

\section{Tujuaan Penelitian}

Berdasarkan rumusan masalah maka tujuan penelitian ini adalah:

1. Untuk mengetahui kompetensi guru di SMK Kartika X-2.
2. Untuk mengetahuikinerja guru di SMK Kartika X-2.

3. Untuk mengetahui seberapa besar pengaruh kompetensi terhadap kinerja guru SMK Kartika X-2.

\section{E. Kerangka Berfikir}

Kerangka berfikir adalah sintesa tentang hubungan antara variabel yang disusun dari berbagai teori yang telah di deskripsikan. (sugiyono 2016:89)

Berdasarkan kerangka berfikir di atas, maka pengaruh kompetensi terhadap kinerja guru dapat di gambarkan sebagai berikut :

Pengaruh Kompetensi Terhadap Kinerja Guru pada SMK Kartika X-2.

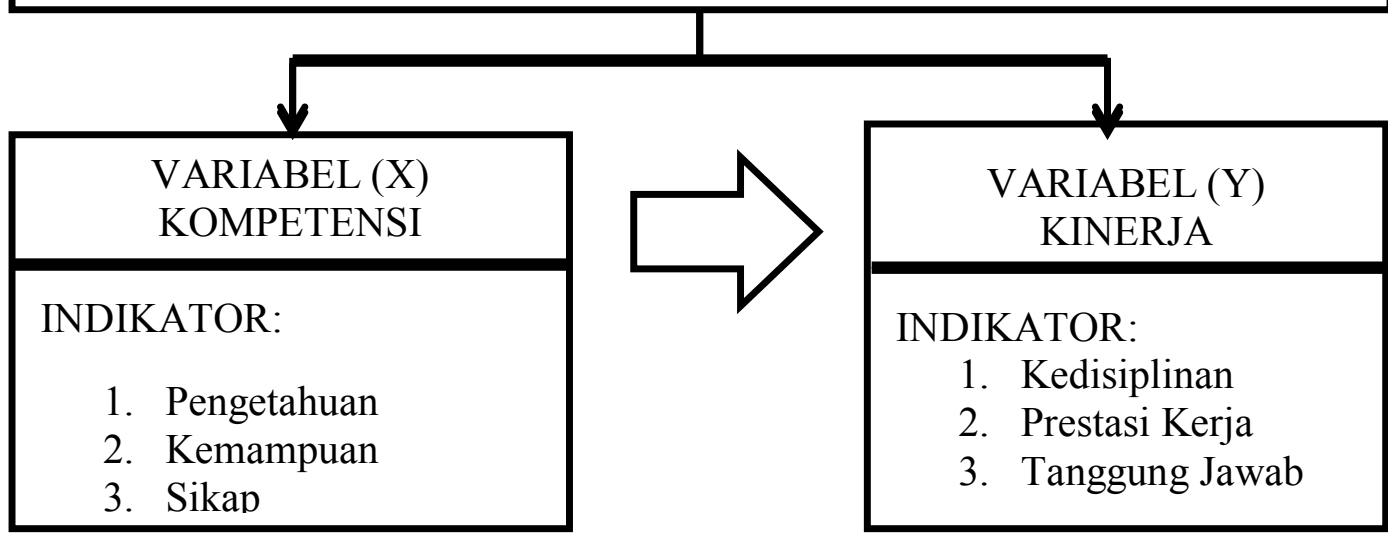

Sumber : Wibowo (2015:272)

Sumber: Hasibuan (2017:34)

Gambar 1.1

Kerangka Berpikir

\section{F. Hipotesis}

$\begin{aligned} \mathrm{Ho}= & 0: \text { Tidak terdapat } & \text { Ha } & \neq 0 \quad: \text { Terdapat pengaruh } \\ & \text { pengaruh yang signifikan } & & \text { yang signifikan antara } \\ & \text { antara kompetensi } & & \text { kompetensi terhadap } \\ & \text { terhadap kinerja guru } & & \text { kinerja guru SMK Kartika } \\ & \text { SMK Kartika X-2. } & & \text { X-2. }\end{aligned}$




\section{TINJAUAN PUSTAKA}

\section{A. Kompetensi}

\section{Departemen}

Nasional

(2006:2)

Pendidikan memberi pengertian kompetensi adalah kemampuan bersikap, berpikir dan bertindak secara konsisten sebagai perwujudan dari pengetahuan, sikap dan keterampilan yang dimiliki peserta didik.

Kompetensi merupakan salah satu faktor penentu keberhasilan atau tercapainya tujuan organisasi.

Kompetensi adalah terminologi yang sering didengar dan diucapkan banyak orang, khususnya yang terkait dengan pengembangan sumber daya manusia. Akan tetapi seringkali persepsi, pemahaman dan makna terminologi itu tidak sama atau saling dipertukarkan dengan terminologi lain. Ada yang menginterpretasikan kompetensi sepadan dengan layak (feasible), handal (fellable), sosok, dapat dipercaya dan cerdas.

Menurut Wibowo (2015:271) kompetensi adalah suatu kemampuan untuk melaksanakan atau melakukan suatu pekerjaan atau tugas yang dilandasi atas keterampilan dan pengetahuan serta didukung oleh sikap kerja yang dituntut oleh pekerjaan tersebut. Dengan demikian kompetensi menunjukan keterampilan atau pengetahuan yang dicirikan oleh profesionalisme dalam suatu bidang tertentu sebagai sesuatu yang terpenting, sebagai unggulan bidang tersebut.

Dengan demikian, seseorang pelaksana yang unggul adalah mereka yang menunjukan kompetensi pada skala tingkat lebih tinggi, dengan frekuensi lebih tinggi, dan dengan hasil lebih baik daripada pelaksanaan biasa atau rata-rata.

\section{B. Kinerja}

Menurut Anwar Prabu Mangkunegara (2013:67) Pengertian kinerja (prestasi kerja) adalah hasil kerja secara kualitas dan kuantitas yang dicapai oleh seorang pegawai dalam melaksanakan tugasnya sesuai dengan tanggung jawab yang diberikan kepadanya.

Menurut Hasibuan (2016:34) mengemukakan kinerja adalah suatu hasil kerja yang dicapai sesekiorang dalam melaksanakan tugas-tugas yang dibebankan kepadanya yang didasarkan atas kecakapan, pengalaman dan keunggulan serta waktu.

\section{METODOLOGI PENELITIAN}

Penelitian dilaksanakan di SMK KARTIKA X-2, Jl. Anggrek Pesanggrahan - Kota Jakarta Selatan, Jenis penelitian yang digunakan adalah kausalitas yakni tipe penelitian yang berkaitan dengan karakteristik masalah berupa hubungan sebab akibat antar dua variabel atau lebih. Penelitian ini ditujukan untuk mengetahui seberapa besar pengaruh antara variabel kompetensi dan kinerja.Dalam penelitian ini yang menjadi populasi adalah 53 orang pada SMK KARTIKA X-2, teknik pengambilan sampel yang digunakan dalam penelitian ini adalah teknik sampling jenuh. Sampling jenuh adalah teknik penentuan sampel bila semua anggota populasi digunakan sebagai sampel (Sugiyono, 2016:124). 


\section{HASIL PENELITIAN DAN \\ PEMBAHASAN}

\section{A. Profil Responden}

1. Data Responden Berdasarkan Jenis Kelamin responden dalam penelitian ini dikelompokan menjadi 2 (dua) kelompok yaitu jenis kelamin laki-laki dan jenis kelamin perempuan. Data mengenai jenis kelamin responden ini adalah sebagai berikut:

\section{Tabel 4.1}

Data Responden Berdasarkan Jenis Kelamin

\begin{tabular}{|c|c|c|c|}
\hline $\begin{array}{c}\text { No } \\
.\end{array}$ & $\begin{array}{c}\text { Jenis } \\
\text { Kelamin }\end{array}$ & $\begin{array}{c}\text { Jumla } \\
\text { h }\end{array}$ & $\begin{array}{c}\text { Presenta } \\
\text { se (\%) }\end{array}$ \\
\hline 1 Laki-laki & 33 & $62,26 \%$ \\
\hline $\begin{array}{c}2 \\
\text { Perempua } \\
\text { n }\end{array}$ & 20 & $37,74 \%$ \\
\hline & Jumlah & $\mathbf{5 3}$ & $\mathbf{1 0 0 \%}$ \\
\hline
\end{tabular}

Sumber : Data primer yang diolah, 2018

Berdasarkan tabel 4.1 diatas nampak bahwa responden dalam penelitian ini laki-laki yaitu sebanyak 33 orang atau sebesar 62,26\%. Sedangkan responden perempuan sebanyak 20 orang atau sebesar $37,74 \%$ dengan cara perhitungan $\frac{\text { jumla } h \text { responden }}{53} \times 100 \quad$ maka didapatkan hasil tersebut.

2. Data Responden Berdasarkan Usia Karakteristik responden dalam penelitian ini berdasarkan usia disajikan dalam tabel 4.2 dibawah ini:

Tabel 4.2

Data Responden Berdasarkan Usia

\begin{tabular}{|c|c|c|c|}
\hline $\begin{array}{c}\text { No } \\
.\end{array}$ & Usia & $\begin{array}{c}\text { Jumla } \\
\mathbf{h}\end{array}$ & $\begin{array}{c}\text { Persentase( } \\
\mathbf{\%})\end{array}$ \\
\hline & $\begin{array}{l}21-30 \\
\text { tahun }\end{array}$ & 14 & $26,42 \%$ \\
\hline 2 & $\begin{array}{c}31-40 \\
\text { tahun }\end{array}$ & 15 & $28,30 \%$ \\
\hline
\end{tabular}

\begin{tabular}{|c|c|c|}
\hline $\begin{array}{c}41-45 \\
\text { tahun }\end{array}$ & 7 & $13,21 \%$ \\
\hline $\begin{array}{c}>45 \\
\text { tahun }\end{array}$ & 17 & $32,07 \%$ \\
\hline $\begin{array}{c}\text { Jumla } \\
\mathbf{h}\end{array}$ & $\mathbf{5 3}$ & $\mathbf{1 0 0 \%}$ \\
\hline
\end{tabular}

Sumber : Data primer yang

diolah, 2018

Berdasarkan data diatas dapat dilihat bahwa pada SMK Kartika X-2 Jakarta Selatan, usia 21-30 tahun yaitu 14 orang atau $26,42 \%, 31-40$ tahun yaitu 15 orang atau $28,30 \%$, 41-45 tahun yaitu 7 orang atau $13,21 \%$ dan $>45$ tahun yaitu 17 orang atau $32,07 \%$ dengan cara perhitungan $\frac{\text { jumla } h \text { responden }}{53} \times 100$ maka didapatkan hasil tersebut.

3. Data Responden Berdasarkan Pendidikan Karakteristik responden dalam penelitian ini berdasarkan pendidikan sajikan dalam tabel 4.3 dibawah ini.

Tabel 4.3

Data Responden Berdasarkan Pendidikan

\begin{tabular}{|c|c|c|c|}
\hline $\begin{array}{c}\text { N } \\
\text { o. }\end{array}$ & $\begin{array}{c}\text { Pendidi } \\
\text { kan }\end{array}$ & $\begin{array}{c}\text { Juml } \\
\text { ah }\end{array}$ & $\begin{array}{c}\text { Persentase } \\
(\mathbf{\%})\end{array}$ \\
\hline & S2 & 11 & $20,75 \%$ \\
\hline & S1 & 33 & $62,26 \%$ \\
\hline & D 3 & 1 & $1,90 \%$ \\
\hline & SMA & 8 & $15,09 \%$ \\
\hline & Jumlah & $\mathbf{5 3}$ & $\mathbf{1 0 0 \%}$ \\
\hline
\end{tabular}

Sumber: Data primer yang diolah, 2018

Berdasarkan dara diatas dapat dilihat bahwa pada SMK Kartika X-2 Jakarta Selatan, jenjang pendidikan S2 yaitu 11 orang atau $20,75 \%, \mathrm{~S} 1$ yaitu 33 orang atau $62,26 \%$, D3 yaitu 1 orang atau $1,90 \%$, SMA yaitu 8 orang atau $15,09 \%$ dengan cara perhitungan $\frac{\text { jumla h responden }}{53} \times 100$ maka didapat hasil tersebut. 


\section{B. Analisis Data Penelitian}

1. Analisis Varisbel Kompetensi (X)

Hasil jawaban dari 53 responden terhadap kompetensi yang terdiri dari 10 unsur pernyataan, jawaban tersebut kemudian dianalisa dengan menggunakan persentase jawaban sebagai berikut: Kompetensi yang terdapat pada SMK Kartini X-2 Jakarta Selatan, mendapat respon baik. Penulis menyimpulkan berdasarkan hasil jawaban seluruh responden yang berjumlah 53 orang dengan 10 pernyataan dengan menjawab "Sangat Setuju" sebanyak 261 atau 50\%, jawaban "Setuju" sebanyak 197 atau 37\%, jawaban "Ragu-Ragu" sebanyak 40 atau 7\%, jawaban "Tidak Setuju" sebanyak 30 atau 5\% dan jawaban "Sangat Tidak Setuju" sebanyak 2 atau 1\%.

2. Analisis Variabel Kinerja Guru (Y)

Hasil jawaban dari 53 responden terhadapan Kinerja Guru yang terdiri dari 10 unsur pernyataan, jawaban tersebut kemudian dianalisis dengan menggunakan presentase jawaban semuanya itu tertuang dan dijelaskan sebagai berikut:Kinerja Guru yang terdapat pada SMK Kartika X-2 Jakarta Selatan, mendapat respon baik. Penulis menyimpulkan berdasarkan hasil jawaban seluruh responden yang berjumlah 53 orang dengan 10 pernyataan, dengan menjawab "Sangat Setuju" sebanyak 341atau $64 \%$, jawaban "Setuju" sebanyak 137 atau 26\%, jawaban "RaguRagu" sebanyak 21 atau 4\%, jawaban "Tidak Setuju" sebanyak 31 atau 6\% dan jawaban "Sangat
Tidak Setuju" sebanyak 0 atau $0 \%$.

\section{Hasil Penelitian}

\section{Uji Validitas}

Untuk menentukan valid atau tidaknya setiap butir pernyataan variabel Kompetensi (X) dan Kinerja Guru (Y) maka dapat menghitungnya menggunakan instrument validitas, berikut adalah rumus untuk menentukan validitas instrumen dari setiap pernyataan.

a. Variabel X (Kompetensi)

$$
\begin{gathered}
r_{x y}=\frac{n(\Sigma X Y)-(\Sigma X) \cdot(\Sigma Y)}{\sqrt{n \cdot \Sigma X^{2}}-(\Sigma X)^{2} \cdot \sqrt{n \cdot \Sigma Y^{2}-(\Sigma Y)^{2}}} \\
=\frac{5108}{\sqrt{11573,37}} \\
=0,441
\end{gathered}
$$

Selanjutnya, nilai $r$ hitung dibandingkan dengan $\mathrm{r}$ tabel pada tingkat alfa (taraf kesalahan) 5\%:

$\mathrm{R}$ hitung $>\mathrm{r}$ tabel $(\mathrm{a}=5 \%)$, maka instrumrn (alat ukur) valid $r$ hitung $<$ $\mathrm{r}$ tabel $(\mathrm{a}=5 \%)$, maka unstrumen (alat ukur) tidak valid dengan demikian, karena $r$ hitung hasil perhitungan lebih besar dari pada $r$ tabel $(0,441>$ 0,271 ) sehingga di simpulkan bahwa butir pernyataan pada instrumen no. 1 variabel dapat di katakan valid.

Tabel 4.4

Hasil Analisis Item Instrumen Kompetensi

\begin{tabular}{|c|c|c|c|}
\hline $\begin{array}{c}\text { Butir } \\
\text { Pernyataa } \\
\mathrm{n}\end{array}$ & $\begin{array}{c}\text { r- } \\
\text { hitung }\end{array}$ & $\begin{array}{c}\text { r- } \\
\text { tabel }\end{array}$ & $\begin{array}{c}\text { Ketera } \\
\text { ngan }\end{array}$ \\
\hline 1 & 0,441 & $\begin{array}{c}0,27 \\
1\end{array}$ & VALID \\
\hline 2 & 0,588 & $\begin{array}{c}0,27 \\
1\end{array}$ & VALID \\
\hline 3 & 0,534 & $\begin{array}{c}0,27 \\
1\end{array}$ & VALID \\
\hline
\end{tabular}




\begin{tabular}{|c|c|c|l|}
\hline 4 & 0,461 & $\begin{array}{c}0,27 \\
1\end{array}$ & VALID \\
\hline 5 & 0,518 & $\begin{array}{c}0,27 \\
1\end{array}$ & VALID \\
\hline 6 & 0,456 & $\begin{array}{c}0,27 \\
1\end{array}$ & VALID \\
\hline 7 & 0,592 & $\begin{array}{c}0,27 \\
1\end{array}$ & VALID \\
\hline 8 & 0,508 & $\begin{array}{c}0,27 \\
1\end{array}$ & VALID \\
\hline 9 & 0,504 & $\begin{array}{c}0,27 \\
1\end{array}$ & VALID \\
\hline 10 & 0,460 & $\begin{array}{c}0,27 \\
1\end{array}$ & VALID \\
\hline
\end{tabular}

Data menggunakan Microsoft Excel 2010

Dari tabel rangkuman hasil perhitungan validitas instrumen pada variabel kompetensi diatas dapat dilihat bahwa 10 butir pernyataan yang dijadikan sebagaiinstrumen pada variabel kompetensi dapat dikatakan valid, karena nilai $r$ hitung dan masing-masing butir pernyataan lebih besar dari pada nilai $\mathrm{r}$ tabel pada tingkat alfa (taraf kesalahan) $5 \%$, didapatkan nilai $r$ tabel sebesar 0,271 . Dengan nilai tertinggi sebesar 0,592 dan dengan nilai terendah sebesar 0,271 .

b. Variabel Y (Kinerja Guru)

Tabel 4.5

Hasil Analisis Item Instrumen Kinerja Guru

\begin{tabular}{|c|c|c|c|}
\hline $\begin{array}{c}\text { Butir } \\
\text { Pernyata } \\
\text { an }\end{array}$ & $\begin{array}{c}\text { r- } \\
\text { hitun } \\
\mathbf{g}\end{array}$ & $\begin{array}{c}\text { r- } \\
\text { tabel }\end{array}$ & $\begin{array}{c}\text { Ketera } \\
\text { ngan }\end{array}$ \\
\hline 1 & 0,706 & $\begin{array}{c}0,27 \\
1\end{array}$ & VALID \\
\hline 2 & 0,775 & $\begin{array}{c}0,27 \\
1\end{array}$ & VALID \\
\hline 3 & 0,655 & $\begin{array}{c}0,27 \\
1\end{array}$ & VALID \\
\hline 4 & 0,876 & $\begin{array}{c}0,27 \\
1\end{array}$ & VALID \\
\hline 5 & 0,853 & 0,27 & VALID \\
\hline
\end{tabular}

\begin{tabular}{|c|c|c|l|}
\hline & & 1 & \\
\hline 6 & 0,817 & $\begin{array}{c}0,27 \\
1\end{array}$ & VALID \\
\hline 7 & 0,834 & $\begin{array}{c}0,27 \\
1\end{array}$ & VALID \\
\hline 8 & 0,788 & $\begin{array}{c}0,27 \\
1\end{array}$ & VALID \\
\hline 9 & 0,824 & $\begin{array}{c}0,27 \\
1\end{array}$ & VALID \\
\hline 10 & 0,850 & $\begin{array}{c}0,27 \\
1\end{array}$ & VALID \\
\hline
\end{tabular}

Data menggunakan Microsoft Excel 2010

Dari tabel rangkuman hasil perhitungan validitas instrumen pada variabel kinerja guru diatas dapat dilihat bahwa 10 butir pernyataan yang dijadikan sebagaiinstrumen pada variabel kinerja guru dapat dikatakan valid, karena nilai $r$ hitung dan masing-masing butir pernyataan lebih besar dari pada nilai $r$ tabel pada tingkat alfa (taraf kesalahan) $5 \%$, didapatkan nilai $\mathrm{r}$ tabel sebesar 0,271 . Dengan nilai tertinggi sebesar 0,876 dan dengan nilai terendah sebesar 0,271.

2. Uji Reliabilitas

Metode yang digunakan dalam penelitian ini untuk menghitung reliabilitas yaitu dengan menggunakan metode cronbach alpha.dimana yang digunakan adalah sebagai berikut:

a. Uji reliabilitas instrument kompetensi (X)

b. $\quad S i=\frac{S X_{i}^{2}-\frac{\left(S X_{i}\right)^{2}}{n}}{n}$

Contoh pehitungan butir 1

$$
\mathrm{Si}=\frac{939^{2}-\frac{(217)^{2}}{53}}{53}=0,953
$$


Table 4.6

Perhitungan Uji Reliabilitas Variabel Kompetensi (X)

\begin{tabular}{|l|l|l|l|l|l|l|l|l|l|l|l|}
\hline $\begin{array}{l}\text { Buti } \\
\text { r }\end{array}$ & S1 & S2 & S3 & S4 & S5 & S6 & S7 & S8 & S9 & S10 & $\begin{array}{l}\text { JUMLA } \\
\text { H }\end{array}$ \\
\hline $\mathbf{X}$ & 217 & 228 & 222 & 232 & 214 & 225 & 242 & 233 & 233 & 229 & 2275 \\
\hline $\mathbf{X 2}$ & 939 & $\begin{array}{l}100 \\
8\end{array}$ & 966 & $\begin{array}{l}105 \\
2\end{array}$ & $\begin{array}{l}920 \\
\begin{array}{l}100 \\
9\end{array}\end{array}$ & $\begin{array}{l}112 \\
8\end{array}$ & $\begin{array}{l}105 \\
5\end{array}$ & $\begin{array}{l}105 \\
7\end{array}$ & $\begin{array}{l}102 \\
5\end{array}$ & \\
\hline Si & $\begin{array}{l}0,95 \\
3\end{array}$ & $\begin{array}{l}0,51 \\
3\end{array}$ & $\begin{array}{l}0,68 \\
1\end{array}$ & $\begin{array}{l}0,68 \\
8\end{array}$ & $\begin{array}{l}1,05 \\
5\end{array}$ & $\begin{array}{l}1,01 \\
5\end{array}$ & $\begin{array}{l}0,43 \\
4\end{array}$ & $\begin{array}{l}0,57 \\
9\end{array}$ & $\begin{array}{l}0,61 \\
7\end{array}$ & $\begin{array}{l}0,67 \\
1\end{array}$ & 7,206 \\
\hline
\end{tabular}

Total varian score butir pernyataan $=$ 7,206

menghitung varian total dengan rumus

$$
\begin{aligned}
& \mathrm{St}=\frac{S X_{i}^{2}-\frac{\left(S X_{i}\right)^{2}}{n}}{n} \\
& =\frac{98597-\frac{(2275)^{2}}{53}}{53} \\
& S t=\frac{98597-97653}{53} \\
& =17,811
\end{aligned}
$$

$r_{11} \geq r_{\text {tabel }}(\geq=5 \%)$, maka instrumen (alat ukur) dinyatakan reliabel.

$r_{11} \leq r_{\text {tabel }}(\leq=5 \%)$, maka instrumen (alat ukur) dinyatakan tidak reliabel. Dengan demikian, karena hasil perhitungan $r_{11}$ lebih besar dari pada $r_{\text {tabel }}(0,596 \geq 0,271)$ sehingga instrumen dapat dikatkan reliabel.

c. Uji reliabilitas instrument kinerja guru $(\mathrm{Y})$

$$
\text { d. ) }
$$

Menghitung nilai koefisien reliabilitas dengan metode cronbach alpha dengan rumus:

$$
r_{11}=\left(\frac{k}{k-1}\right) \cdot\left(1-\frac{\sum S_{i}}{S_{t}}\right)
$$

$$
\begin{aligned}
& r_{11}=\left(\frac{k}{k-1}\right)\left(1-\frac{\sum S i}{S t}\right) \\
& r_{11}=\left(\frac{53}{53-1}\right)\left(1-\frac{7,206}{17,811}\right)=0,596
\end{aligned}
$$

Selanjutnya, nilai $\quad r 1$ dibandingkan dengan $r_{\text {tabel }}$ pada tingkat alfa (taraf kesalahan) $5 \%$. Kriteria keputusan :

$$
S i=\frac{S X_{i}^{2}-\frac{\left(S X_{i}\right)^{2}}{n}}{n}
$$

Contoh pehitungan butir 1

Table 4.7

$\mathrm{Si}=\frac{1033^{2}-\frac{(229)^{2}}{53}}{53}=0,822$

\section{Perhitungan Uji Reliabilitas Variabel Kinerja (Y)}

\begin{tabular}{|l|l|l|l|l|l|l|l|l|l|l|l|}
\hline BUTIR & S1 & S2 & S3 & S4 & S5 & S6 & S7 & S8 & S9 & S10 & JUMLAH \\
\hline Y & 229 & 231 & 223 & 243 & 243 & 238 & 243 & 238 & 243 & 247 & 2378 \\
\hline Y2 & 1033 & 1041 & 983 & 1145 & 1145 & 1104 & 1147 & 1106 & 1149 & 1177 & \\
\hline Si & 0,822 & 0,645 & 0,844 & 0,582 & 0,582 & 0,665 & 0,620 & 0,703 & 0,658 & 0,488 & 6,609 \\
\hline
\end{tabular}

Total varian score butir pernyataan $=$ 6,609

menghitung variantotal dengan rumus

$\mathrm{St}=\frac{S X_{i}^{2}-\frac{\left(S X_{i}\right)^{2}}{n}}{n}$

$$
=\frac{108890-\frac{(2378)^{2}}{53}}{53}
$$

$$
\begin{gathered}
S t=\frac{108890-106695}{53} \\
=41,415
\end{gathered}
$$


Menghitung nilai koefisien reliabilitas dengan metode cronbach alpha dengan rumus:

$r_{11}=\left(\frac{k}{k-1}\right)\left(1-\frac{\sum S i}{S t}\right)$

$r_{11}=\left(\frac{53}{53-1}\right)\left(1-\frac{6,609}{41,415}\right)=0,841$

Selanjutnya, nilai $\quad r 1$ dibandingkan dengan $r_{\text {tabel }}$ pada tingkat alfa (taraf kesalahan) 5\%. Kriteria keputusan :

$r_{11} \geq r_{\text {tabel }}(\geq=5 \%)$, maka instrumen (alat ukur) dinyatakan reliabel.

$r_{11} \leq r_{\text {tabel }}(\leq=5 \%)$, maka instrumen (alat ukur) dinyatakan tidak reliabel. Dengan demikian, karena hasil perhitungan $r_{11}$ lebih besar dari pada $r_{\text {tabel }}(0,841 \geq 0,271)$ sehingga instrumen dapat dikatkan reiabel.
1. Analisis Variabel $\mathrm{X}$ (Kompetensi) dan Y (Kinerja Guru)

2. Analisis Korelasi Variabel $X$ (Kompetensi) dan Y (Kinerja Guru)

Analisis kolerasi dalam penelitian ini untuk mengetahui seberapa besar hubungan antara variabel bebas $(\mathrm{X})$ yaitu Kompetensi dan variabel terikat (Y) yaitu Kinerja Guru. Rumus yang digunakan untuk meghitung kolerasi antara variabel bebas (X) dengan terikat (Y) adalah Kolerasi Product Momen :

Dimana rumusnya adalah sebagai berikut :

$\mathrm{r}_{\mathrm{xy}}=\frac{n \sum x y-\sum x \sum y}{\sqrt{\left(\mathrm{n} \sum \mathrm{x}^{2}-\left(\sum x\right)^{2}\right) / n \sum y^{2}-\left(\sum y\right)^{2}}}$

Tabel 4.8

Analisis Pengaruh Antara Kompetensi (X) dan Kinerja Guru (Y)

\begin{tabular}{|c|c|c|c|c|c|}
\hline No & $\mathbf{X}$ & $\mathbf{Y}$ & $\mathbf{X}^{\mathbf{2}}$ & $\mathbf{Y}^{\mathbf{2}}$ & $\mathbf{X Y}$ \\
\hline 1 & 43 & 43 & 1849 & 1849 & 1849 \\
\hline 2 & 40 & 46 & 1600 & 2116 & 1840 \\
\hline 3 & 46 & 48 & 2116 & 2304 & 2208 \\
\hline 4 & 47 & 48 & 2209 & 2304 & 2256 \\
\hline 5 & 41 & 49 & 1681 & 2401 & 2009 \\
\hline 6 & 44 & 47 & 1936 & 2209 & 2068 \\
\hline 7 & 40 & 44 & 1600 & 1936 & 1760 \\
\hline 8 & 43 & 47 & 1849 & 2209 & 2021 \\
\hline 9 & 44 & 48 & 1936 & 2304 & 2112 \\
\hline 10 & 45 & 48 & 2025 & 2304 & 2160 \\
\hline 11 & 43 & 45 & 1849 & 2025 & 1935 \\
\hline 12 & 44 & 48 & 1936 & 2304 & 2112 \\
\hline 13 & 42 & 47 & 1764 & 2209 & 1974 \\
\hline 14 & 46 & 45 & 2116 & 2025 & 2070 \\
\hline 15 & 44 & 49 & 1936 & 2401 & 2156 \\
\hline 16 & 46 & 46 & 2116 & 2116 & 2116 \\
\hline 17 & 44 & 49 & 1936 & 2401 & 2156 \\
\hline 18 & 43 & 45 & 1849 & 2025 & 1935 \\
\hline 19 & 41 & 48 & 1681 & 2304 & 1968 \\
\hline
\end{tabular}


JENIUS

\begin{tabular}{|c|c|c|c|c|c|}
\hline 20 & 40 & 45 & 1600 & 2025 & 1800 \\
\hline 21 & 40 & 35 & 1600 & 1225 & 1400 \\
\hline 22 & 40 & 49 & 1600 & 2401 & 1960 \\
\hline 23 & 44 & 20 & 1936 & 400 & 880 \\
\hline 24 & 47 & 47 & 2209 & 2209 & 2209 \\
\hline 25 & 44 & 47 & 1936 & 2209 & 2068 \\
\hline 26 & 40 & 45 & 1600 & 2025 & 1800 \\
\hline 27 & 48 & 44 & 2304 & 1936 & 2112 \\
\hline 28 & 44 & 49 & 1936 & 2401 & 2156 \\
\hline 29 & 47 & 48 & 2209 & 2304 & 2256 \\
\hline 30 & 45 & 48 & 2025 & 2304 & 2160 \\
\hline 31 & 43 & 48 & 1849 & 2304 & 2064 \\
\hline 32 & 47 & 46 & 2209 & 2116 & 2162 \\
\hline 33 & 49 & 44 & 2401 & 1936 & 2156 \\
\hline 34 & 40 & 48 & 1600 & 2304 & 1920 \\
\hline 35 & 46 & 45 & 2116 & 2025 & 2070 \\
\hline 36 & 44 & 46 & 1936 & 2116 & 2024 \\
\hline 37 & 44 & 46 & 1936 & 2116 & 2024 \\
\hline 38 & 45 & 47 & 2025 & 2209 & 2115 \\
\hline 39 & 44 & 20 & 1936 & 400 & 880 \\
\hline 40 & 45 & 47 & 2025 & 2209 & 2115 \\
\hline 41 & 40 & 46 & 1600 & 2116 & 1840 \\
\hline 42 & 44 & 48 & 1936 & 2304 & 2112 \\
\hline 43 & 42 & 48 & 1764 & 2304 & 2016 \\
\hline 44 & 40 & 46 & 1600 & 2116 & 1840 \\
\hline 45 & 42 & 46 & 1764 & 2116 & 1932 \\
\hline 46 & 44 & 50 & 1936 & 2500 & 2200 \\
\hline 47 & 42 & 42 & 1764 & 1764 & 1764 \\
\hline 48 & 42 & 45 & 1764 & 2025 & 1890 \\
\hline 49 & 18 & 21 & 324 & 441 & 378 \\
\hline 50 & 40 & 45 & 1600 & 2025 & 1800 \\
\hline 51 & 42 & 45 & 1764 & 2025 & 1890 \\
\hline 52 & 47 & 47 & 2209 & 2209 & 2209 \\
\hline 53 & 40 & 45 & 1600 & 2025 & 1800 \\
\hline$\sum$ & 2275 & 2378 & 98597 & 108890 & 102707 \\
\hline
\end{tabular}

$$
\mathrm{r}_{\mathrm{xy}}=\frac{n \sum x y-\sum x \sum y}{\sqrt{\left(\mathrm{n} \sum \mathrm{x}^{2}-\left(\sum x\right)^{2}\right) \ln \sum y^{2}-\left(\sum y\right)^{2}}}
$$

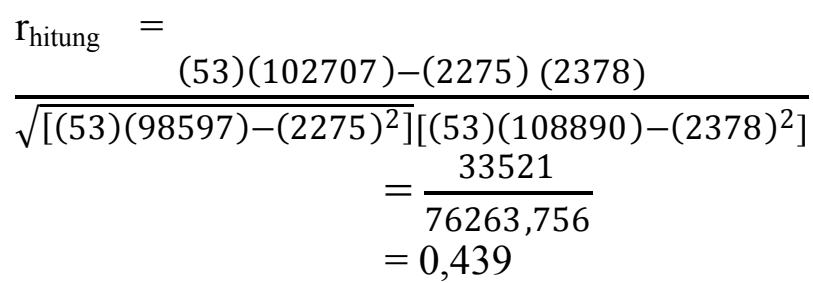


Tabel 4. 9

Pedoman untuk memberikan Interprestasi Koefisien Kolerasi

\begin{tabular}{|c|c|}
\hline Interval Koefisien & $\begin{array}{c}\text { Tingkat } \\
\text { Hubungan }\end{array}$ \\
\hline $0,00-0,19$ & Sangat Lemah \\
\hline $0,20-0,399$ & Lemah \\
\hline $\mathbf{0 , 4 0}-\mathbf{0 , 5 9 9}$ & Cukup Kuat \\
\hline $0,60-0,799$ & Kuat \\
\hline $0,80-1,000$ & Sangat Kuat \\
\hline
\end{tabular}

Sumber :Sugiono

(2013:184)

Dari analisis perhitungan menggunakan rumus Koefisien Kolerasi Persen ada pengaruh positif antara Kompetensi dan Kinerja Guru sebesar $r=0,4$ yang termasuk kategori cukup kuat.

3. Analisis Regresi Linear Sederhana

\section{Analisis Regresi Linier} Sederhana digunakan untuk melakukan seberapa tinggi nilai variabel dependen bila nilai variabel independen di rubahrubah atau manipulasi. Rumus yang digunakan dalam analisis regresi linear sederhana yaitu ; $\mathrm{Y}=\mathrm{a}+\mathrm{bX}$

$$
\begin{array}{r}
a=\frac{\Sigma y-b \Sigma x}{n} \\
b=\frac{n \sum x y-\Sigma x \Sigma y}{n \sum x^{2}-(\Sigma x)^{2}} \\
b=\frac{n \sum x y-\Sigma x \Sigma y}{n \sum x^{2}-(\Sigma x)^{2}} \\
b=\frac{361220}{50016} \\
b=7,222 \\
a=\frac{\Sigma y-b \Sigma x}{n} \\
a=13,867 \\
\mathrm{Y}=13,867+7,222 \mathrm{X}
\end{array}
$$

Berdasarkan hasil perhitungan diatas dapat dijelaskan sebagai berikut :

a. Nilai konstanta intersep sebesar 13,867, merupakan nilai konstanta menyatakan bahwa apabila $X$ $=0$, maka nilai $\mathrm{Y}=13,867$.

b. Nilai koefisien regresi variabel Kompetensi (X) terhadap variabel Kinerja (Y) adalah sebesar 7,222. Hal ini berarti jika kompetensi (X) naik 1 satuan maka akan meningkatkan kepusan kerja sebesar 7,222.

4. Analisis Koefisien Determinasi

Setelah mengetahui nilai koefisien kolerasi $r_{x y}$ antara variabel $(\mathrm{X})$ dan variabel $(\mathrm{Y})$, selanjutnya dilakukan analisis koefisien determinasi. Tujuan analisis determinasi dalam penelitian ini adalah untuk mengetahui hubungan antara Kompetensi dengan Kinerja Guru dalam persen (\%). $\mathrm{KD}=\mathrm{r}^{2} \times 100 \%$

Hal ini membuktikan bahwa besarnya konsumsi Kompetensi terhadap Kinerja guru sebesar $19,27 \%$ sedangkan sisanya $80,73 \%$ variabel Kinerja dipengaruhi oleh faktor lain atau variabel lainya yang belum diteliti seperti disiplin, personalia, keuangan.

5. Uji t

Uji $t$ dilakukan untuk mengetahui apakah variabel independen secara parsial mempengaruhi variabel dependen dengan asumsi variabel independen lainnya konstan. Untuk mengetahui signifikansi analisis jalur, kita 
bandingkan nilai probabilitas dengan nilai probabilitas signifikansi. Apabila $p$ value $\geq$ 0.05, maka H0 ditolak dan $\mathrm{Ha}$ diterima (model regresi signifikan), dan sebaliknya. Adapun rumusnya adalah sebagai berikut :

$$
\begin{gathered}
t=\frac{r \sqrt{n-2}}{\sqrt{1-r}} \\
=53 \\
\mathrm{r}=0,439 \\
\mathrm{t}_{\text {hitung }}=\frac{r \sqrt{n-2}}{\sqrt{1-r}} \\
=\frac{3,13}{0,749} \\
=4,178
\end{gathered}
$$

Dengan demikian, karena $t_{\text {hitung }}$ lebih besar daripada $t_{\text {tabel }}(4,178>$ 2,008) maka Hoditolak dan $\mathrm{H}_{1}$ diterima, shingga dapat disimpulkan bahwa terdapat kolerasi positif dan pengaruh signifikan Kompetensi terhadap Kinerja Guru SMK Kartika X-2 Pesanggrahan Jakarta Selatan

\section{KESIMPULAN DAN SARAN}

\section{A. Kesimpulan}

Berdasarkan hasil penulisan dan analisis data yang telah dipaparkan pada pembahasan sebelumnya, maka penulis dapat menarik kesimpulan terkait dengan penelitian yang di lakukan di SMK Kartika X-2 sebagai berikut:

1. Kompetensi pada SMK Kartika X-2 Jakarta Selatan sudah baik, dikatakan cukup baik karena hasil perhitungan penelitian tentang kompetensi (Variabel X), hal ini dibuktikan dnegan jawaban responden yang berjumlah 53 orang menyatakan sangat setuju dan setuju sebesar $87 \%$.
2. Kinerja guru pada SMK Kartika X-2 Jakarta Selatan, berdasarkan pada hasil jawaban seluruh responden yang berjumlah 53 orang dengan 10 pernyataan yang menjawab "sangat setuju" sejumlah 341 jawaban (64\%), jawaban "setuju" sejumlah 137 jawaban (26\%).

3. Pengaruh Kompetensi terhadap Kinerja Guru berdasarkan perhitungan angka Koefisien Korelasi adalah sebesar 0,439 yang artinya hubungan Komptensi dengan Kinerja Guru CUKUP KUAT.Terdapat pengaruh yang signifikan antara kompetensi terhadap kinerja guru dengan persamaan regresi $\mathrm{Y}=13,867+$ $7,222 \mathrm{X}$, konstanta 13,867 dan koefisien regresi 7,222 artinya bahwa perubahan $\mathrm{Y}$ searah dengan perubahan $X$, jadi nilai $Y$ akan meningkat jika $X$ meningkat, sebaliknya $\mathrm{Y}$ akan menurun jika $\mathrm{X}$ menurun, sedangkan nilai koefisien determinasi sebesar $19,27 \%$ sedangkan sisanya sebesar $80,73 \%$ dipengaruhi oleh faktor lain. Pengujian hipotesis yang dilakukan dengan diperoleh ( 4,178> 2,008) maka Ho ditolak dan $\mathrm{H} 1$ diterima, shingga dapat disimpulkan bahwa terdapat pengaruh signifikan Kompetensi terhadap Kinerja Guru SMK Kartika X-2 Pesanggrahan Jakarta Selatan.

\section{B. SARAN}

Berdasarkan hasil penelitian, maka penulis memiliki saran-saran terkait dengan kompetensi dan kinerja guru agar lebih baik lagi, yakni sebagai berikut: 
1. Kompetensi guru pada SMK Kartika X-2 Jakarta Selatan sudah cukup baik, namun sekolah harus melakukan perubahan dilihat dari indikator pengetahuan, kemampuan dan sikap berdasarkan hasil kuesioner tidak setuju (TS) sebesar 5\% dan sangat tidak setuju (STS) sebesar 1\% yang artinya kompetensi yang dimiliki guru belum mencapai angka 100\%. Oleh karena itu, kompetensi harus lebih ditingkatkan mulai dari diri sendiri dan dari organisasi.

2. Kinerja Guru pada SMK Kartika X-2 Jakarta Selatan sudah cukup baik, akan tetapi peningkatan kinerja harus terus dilakukan baik dari kedisiplinan, prestasi kerja, dan tanggung jawab dilihat dari hasil kuesioner tidak setuju (TS) sebesar $6 \%$ yang artinya kinerja guru belum mencapai angka $100 \%$ maka untuk mencapai hasil yang optimal dibutuhkan peningkatan kinerja agar sesuai dengan tujuan.

3. Pengaruh kompetensi terhadap kinerja guru berdasarkan hasil koefisien korelasi 0,439 yang artinya hubungan kompetensi dan kinerja guru cukup kuat, sehingga penulis menyarankan agar kompetensi lebih ditingkatkan agar pengaruhnya terhadap kinerja guru menjadi sangat kuat.

\section{DAFTAR PUSTAKA}

Departemen Pendidikan Nasional 2006

Handoko, T. Hani, "Manajemen Sumber Daya Manusia”, cetakan empatbelas,Yogyakarta, BPFE, 2013
Hasibuan,Malayu S.P., "Manajemen Sumber Daya Manusia”, PT Bumi Aksara:Jakarta, 2012

Hasibuan,Malayu S.P., "Manajemen Sumber Daya Manusia”, PT Bumi Aksara:Jakarta, 2013

Hasibuan, Melayu S.P., "Manajemen Sumber Daya Manusia”. Edisi Revisi,Cetakan Kedelapan Belas, Penerbit PT. Bumi Aksara, Jakarta, 2017.

Mangkunegara, Anwar Prabu, "Manajemen Sumber Daya Manusia Perusahaan”, PT.Remaja Rosdakarya, Bandung, 2011

Mangkunegara, Anwar Prabu, "Manajemen Sumber Daya Manusia Perusahaan”, cetakan duabelas, PT.Remaja Rosdakarya, Bandung, 2013

Pengamat Ekonomi Indef 2016

Sugiyono, "Metodologi Penelitian Kuantitatif, Kualitatif dan $R \& D$ ”, cetakan Ke-15 CV. Alfabeta: Bandung. 2016 Sugiono, "Metodelogi

\section{PenelitianKuantitatif,}

Kualitatif dan R\&D", cetakan Ke-11 CV. Alfabeta: Bandung. 2012

Wibowo, "Mananjemen Kinerja”, cetakan kelima, Rajawali Pers, Depok, 2015. 